\title{
Influence of Schneiderian Membrane Perforations on the Prognosis and Outcomes of Lateral Window Sinus Lift Operations: A Retrospective Case Series Study
}

\author{
Marc Hermes ${ }^{1}$, Julian Lommen ${ }^{2}$, Norbert R Kübler ${ }^{3}$, Iryna Lytvyniuk ${ }^{4}$, Daman D Singh ${ }^{5}$, Lara Schorn ${ }^{6}$ and $^{2}$ \\ Henrik Holtmann ${ }^{7 *}$ \\ ${ }^{1} D D S$, junior resident, Department of Oral and Maxillofacial Surgery, Heinrich Heine University, Duesseldorf, Germany \\ ${ }^{2} M D, D D S$, Junior resident, Department of Oral and Maxillofacial Surgery, Heinrich Heine University, Duesseldorf, Germany \\ ${ }^{3}$ MD, DDS, Professor, Department of Oral and Maxillofacial Surgery, Heinrich Heine University, Duesseldorf, Germany \\ ${ }^{4} D D S$, junior resident, Department for conservative dentistry, parodontology and children's dentistry, Heinrich Heine University, \\ Duesseldorf, Germany \\ ${ }^{5}$ MD, DDS; Consultant, Department of Oral and Maxillofacial Surgery, Heinrich Heine University, Duesseldorf, Germany \\ ${ }^{6} \mathrm{MD}$, junior resident, Department of Oral and Maxillofacial Surgery, Heinrich Heine University, Duesseldorf, Germany \\ ${ }^{7}$ MD, DDS, Consultant, Department of Oral and Maxillofacial Surgery, Heinrich Heine University, Duesseldorf, Germany
}

Received: July 02, 2018; Accepted: August 07, 2018; Published: August 20, 2018

*Corresponding author: Henrik Holtmann, Department of Oral and Maxillofacial Surgery, Heinrich Heine University, Duesseldorf, Moorenstraße 5D, 40225 Duesseldorf, Germany, Tel: +49 21181 07428; Fax: +49 21181 18877; E-mail: Henrik.Holtmann@med.uni-duesseldorf.de

\begin{abstract}
Introduction: This study analyzed the influence of Schneiderian membrane perforations covered with collagen membranes on the success of augmentation and implantation as well as the influences of smoking, radiation and chemotherapy.

Patients and Methods: 182 consecutive operated patients with a total of 298 augmented sinuses and 833 inserted implants were analyzed retrospectively. Success rates of sinus augmentations with perforated and unperforated Schneiderian membranes were compared.
\end{abstract}

Results: Perforations of the Schneiderian membrane occurred in $23.2 \%(p<0.001)$. Success rate decreased from $89.4 \%(p<0,001)$ at unperforated sinuses to $80.0 \%(\mathrm{p}=0.005)$ at perforated sinuses for the irradiated patients and from $95.6 \%(p<0,001)$ at unperforated sinuses to $89.8 \%(\mathrm{p}<0.001)$ at perforated sinuses for patients not treated with radiation therapy. Similar results were found for the implant loss rate, which was highest for perforated sinuses at irradiated patients $-43.9 \%(\mathrm{p}=0.023)$ - and lowest for unperforated sinuses at not irradiated patients $-4.5 \%(\mathrm{p}<0.001)$. Comparing membrane perforation to lost implants and failure rate a statistically significant difference could be detected $(\mathrm{p}=0,029)$.

Conclusions: Although Schneiderian membrane was covered with collagen membranes in all cases, perforations still have a negative impact on success rates of augmentation and implant survival. Possible improvements of this method should be investigated in following studies.

Keywords: Radiation therapy; Smoking; Chemotherapy; Sinus augmentation; Implant loss; Implant survival;

\section{Introduction}

Dental implant placement is one of the most popular developments in dentistry and dental surgery of the past decades. By exploring osseointegration and biocompatibility of titanium by Brånemark in 1966, the history of dental implantation began [16]. As a matter of course, the upcoming importance and interest of dental implant placement reached its clinical limits early, due to the fact that implantation itself was not always possible without surgical intervention and preparation. This fact led Tatum Jr. to invent the sinus lift in 1974, which was first published in 1986 [7]. A sinus lift enables augmentation of bone in the maxillary sinus. It became a standard method in dental implantology within the last decades. In comparison to other augmentative procedures a sinus lift has proven to generate reliable outcomes.

The most critical step of a sinus lift is the detachment of the membrane from the bone of the maxillary sinus. This step leads to a very common complication of sinus lift procedure, the perforation of the Schneiderian membrane. Although various improving techniques like piezo surgery (Figure $1 \mathrm{~A}, \mathrm{~B}$ ) were developed to assist the lateral access and to free the bone cover from the Schneiderian membrane, perforations are still an obvious and common problem [8].

After successful preparation of the lateral window and elevation of the Schneiderian membrane, bone graft material is placed into the sinus floor cavity. The filling procedure itself and the type of graft material used create further critical steps 


\section{Series Study}
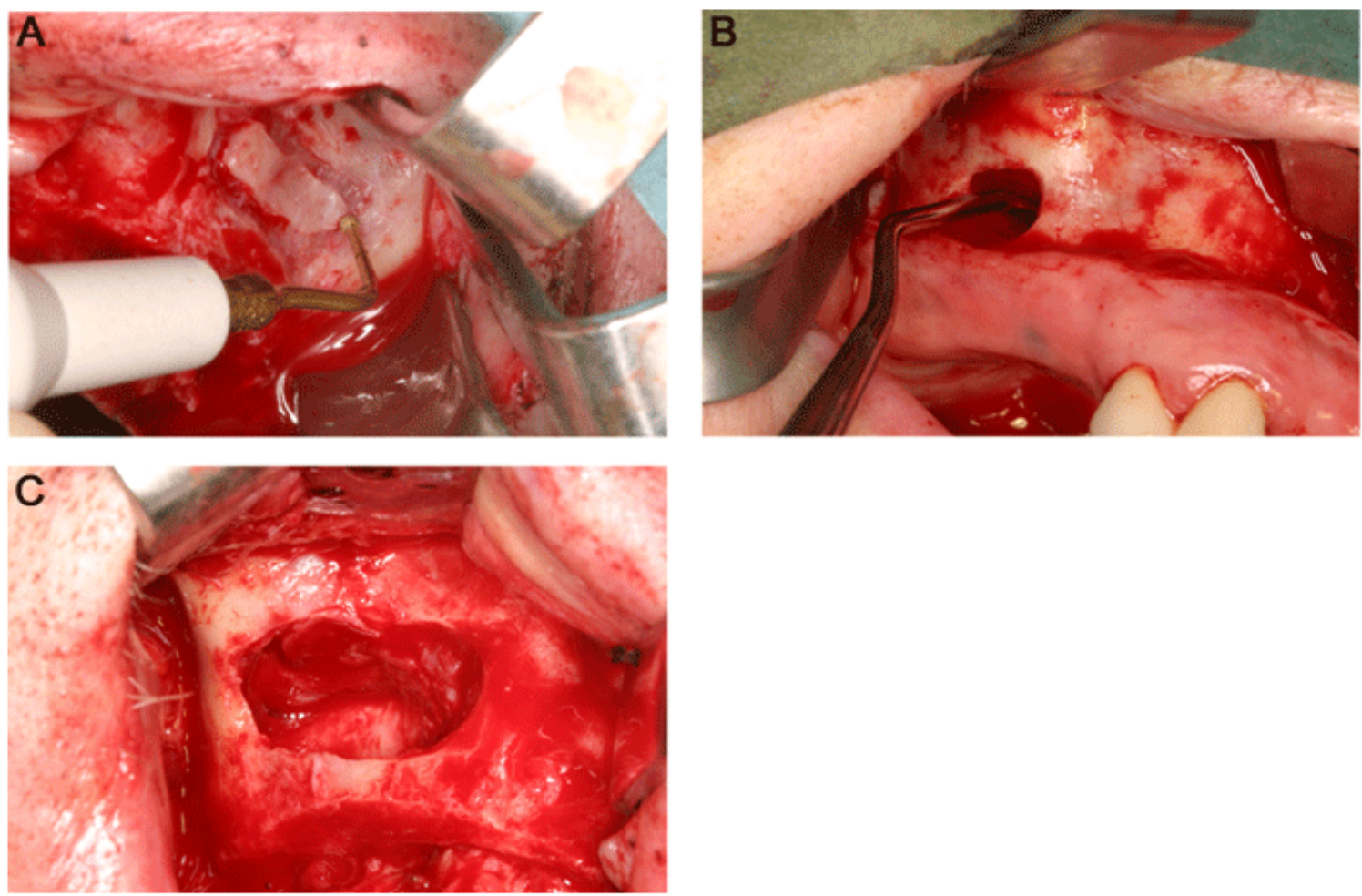

Figure 1: (A) Lateral access to the maxillary sinus. Access preparation is performed by using piezo surgery. (B) Detachment of the Schneiderian membrane from the lateral sinus wall. This is the most critical step due to the risk of possible perforations performed by the instruments. (C) Perforation of the Schneiderian membrane. The visible hole has to be covered by a membrane. Otherwise the upcoming inserted augmented material will be lost by resorption and inflammation.

regarding membrane perforation. Especially xenogenous material may be sharp and spiky and can damage the Schneiderian membrane. Furthermore, strong compression and overfilling of graft material may often cause damage. The perforation of the Schneiderian membrane has a serious impact on the prognosis of the sinus floor elevation procedure, because a perforated membrane can allow the escape of bone substitute into the astral cavity proper. It can also lead to an infection of the bone substitute by germs of the paranasal sinuses.

Although the values of perforation rates in the current literature differ strongly, most authors define perforations of the Schneiderian membrane as the general complication. This was also shown by an systematic literature research by Al-Dajani from 2016 where literature from 1975 up to 2015 was summarized [9]. Moreno Vazquez et al. for example described the damaging of Schneiderian Membrane as a common complication with a rate of $25.7 \%$. However, only $14.9 \%$ of perforated sinuses developed postoperative wound infections [10]. To evaluate the importance of these perforations Nolan et al. compared perforated and unperforated sinuses related to postoperative sinusitis and bone graft survival [11]. The perforation rate amounted to $41.8 \%$ at a total of 359 elevated sinuses. Nevertheless just 24 of the sinus grafts failed (6.7\%). Of these 24 cases 17 had a perforated sinus (70.8\%). The statistics for postoperative infections respectively sinusitis showed similar results with $85 \%$ of them simultaneously having had intraoperative membrane perforation. These findings show that the perforation of Schneiderian membrane has influence on the prognosis and postoperative aftercare.

On the other hand, present articles exist that do not define sinus membrane perforations as an important factor for the prognosis of sinus lift procedures. For example Ardekian, et al. declared that sinus membrane perforations did not show a significant influence on the success rate of immediate placed implants [12].

As presented above, opinions about the influence of Schneiderian membrane perforations vary extensively. This may be due to numerous different treatment methods and differences in study design and analysis.

The aim of this study was to find out, how much influence sinus membrane perforations have on the success of sinus augmentation and implant survival and compared it to other risk factors like smoking and chemotherapy or radiotherapy

\section{Materials and Methods}

A total of 182 consecutively operated patients, who underwent major sinus lift operation, performed by the same surgeon between 2003 and 2013, were included into this retrospective study. 97 patients were females (53.3\%) and 85 males (46.7\%). The youngest patient was - at the moment of the operation - 20 
years old, the oldest was 88 years old (average age 58.4 years, median 61).

Altogether 298 sinus lift operations were performed. They consist of 190 with immediate implantation, and 108 delayed implantations. A group of patients was operated on because of oral squamous cell carcinomas, with or without postoperative radio- and chemotherapy. The principal operation was uniform for all patients. All Schneiderian membranes, whether perforated or not, were covered with a BioMend $®$ (Zimmer Biomet, Munich, Germany) membrane to protect the Schneiderian membrane from damage or alternatively to cover the perforated area. In cases of larger perforations, fibrin glue was used to fix the membranes (18 cases). Analog to the study by Hernandez-Alfaro, et al. [13] we considered Schneiderian membrane perforations with a diameter of $>5 \mathrm{~mm}$ large whereas perforations measuring $<5 \mathrm{~mm}$ were deemed small [13]. The graft material consisted of a combination of autologous bone and xenogenous BioOss ${ }^{\circledR}$ (Geistlich, BadenBaden, Germany) or pure BioOss $\AA$ alone. In 21 cases Grafton $\AA$ DBM-Putty (Argon Dental, Bingen/Rhine, and Germany) was used additionally. Autogenous bone was usually harvested from the iliac crest spongiosa or collected intraoperatively with an Astra Bonetrap ${ }^{\circledR}$ (Dentsply Implants, Mannheim, Germany) while preparing the sinus window. A collagenous membrane - BioMend Extend ${ }^{\circledR}$ (Zimmer Biomet, Munich, Germany) or BioGide ${ }^{\circledR}$ (Geistlich, Baden-Baden, Germany) - was used to cover the access window. Different types of implants of the manufacturers Camlog ${ }^{\circledR} \quad$ (Wimsheim, Germany), Dentsply Implants ${ }^{\circledR}$ (Ankylos ${ }^{\circledR}$, XiVE®, ASTRA TECH $®$ OsseoSpeed [Mannheim, Germany]), Nobel Biocare ${ }^{\circledR}$ (Active, Replace Straight, Replace Tapered, Replace Select Straight, Speedy [Zurich, Switzerland]), Straumann ${ }^{\circledR}$ (Standard Plus, SLActive [Basel, Switzerland]) and 4 Z-Systems ${ }^{\circledR}$ (Z3-411 [Oensingen, Switzerland]) zirconia implants were used. The differentiation of single implant types was not subject of this study.

The data of all 182 patients was collected and processed in accordance to different risk factors. Loss of graft material and loss of implants were defined as the main evaluated outcomes. Failure was defined as any sinus graft that secondarily required debridement and irrigation or failure of any implant within the grafted sinus before loading or within the first year after loading. A successful sinus graft had loaded implants with at least 1 year of follow-up with no mobility or pain on function [11]. Loss of graft material was assumed when a sinus lift was postoperatively infected or deemed insufficient for implantation and/or needed a revision in a second operation, where graft material was completely removed or the sinus lift operation was performed again. The investigated risk factors were perforation of the Schneiderian membrane, smoking, radiation and/or chemotherapy. Each risk factor was compared to the number of lost implants and failure rate.

Three major aspects were of relevance for data analysis; (1) patients that underwent radiation and/or chemotherapy and those who had not been irradiated, (2) patients with perforated and unperforated sinuses and (3) smokers and non-smokers.
Table 1 and 2 show the number of patients, average ages and number of performed sinus lifts e.g. inserted implants for all subdivision stages.

The data was analyzed using the Shapiro-Wilks Test to detect normal distribution. A Kruskal-Wallis Test with post hoc DunnBonferroni adjustment was used to reveal significant differences. The level of significance was set to $p=0.05$. A Students $t$-test was used to determine significances for each subdivision. All calculations were made with IBM ${ }^{\circledR}$ SPSS $®$ Statistics Version 22 (IBM, Armonk, and North Castle, New York, USA).

\section{Results}

Radiation/chemo therapy, membrane perforation and the effect of smoking on the prognosis of sinus lift augmentation were evaluated. While radiation/chemo therapy and the effect of smoking showed no significant effect, membrane perforation made a statistically significant difference $(p=0,029)$ on the number of lost implants and failure rate. Due to the nature of the extracted data a multivariate analysis of variance could not be performed. In order to explore interactions between these factors, further calculations were based onto the three stage system.

As mentioned above the patient numbers, average ages as well as the numbers of augmented sinuses and inserted implants for the single stages are shown in Tables 1 and 2. They are divided into two tables to enable an easy comparison of all groups. In the same way, the results are presented in Tables 3 and 4 . The number of perforations, graft failures and implant losses are shown and the perforation, success and implant failure rates are calculated. Dental implant placement was simultaneous with sinus lifts in all cases. This required a general residual crestal bone height of 3 $\mathrm{mm}$ and primary dental implant stability.

Perforation rates are only shown for the main patient cohort as well as for the first stage, because the following stage divides the sinuses into perforated and unperforated. Success and implant loss rates for all groups are shown, followed by significance value and the absolute numbers. All other values mentioned above (Tables 1-2) were not listed again to ensure a greater clarity.

In our patient cohort, perforations occurred in $23.2 \%$ $(\mathrm{p}<0.001)$ of all performed sinus augmentations. These perforations had an effect on success and implant survival rates. For the irradiated as well as for the non-irradiated patients, the perforated sinuses showed lower success and higher implant loss rates. While the irradiated patients with augmented sinuses where a perforation occurred showed a success rate of $80.0 \%(\mathrm{p}=0.005)$ and implant loss rate of $43.9 \%(\mathrm{p}=0.023)$, the unperforated sinuses in comparison showed a success rate of 89.4\% ( $\mathrm{p}<0.001)$ and implant loss rate of $7.1 \%(\mathrm{p}<0.001)$. Quite similar results were found for the group of patients who had not been treated with radiation and/or chemotherapy. Here the augmentations that exhibited a perforation were successful in $89.8 \%(\mathrm{p}<0.001)$ compared to $95.6 \%(\mathrm{p}<0.001)$ at intact sinuses. The implant loss rate also decreased from $5.9 \%(\mathrm{p}<0.001)$ at perforated to $4.5 \%(\mathrm{p}<0.001)$ at intact sinuses. 
Series Study

Table 1: Comparison of non-irradiated patients with and without perforation of the Schneiderian membrane. Further, comparison of smokers and non-smokers within the groups (demographic and performance data).

\begin{tabular}{|c|c|c|c|c|c|c|}
\hline & No madiation & Perf & ation & No pe & oration & Total \\
\hline & 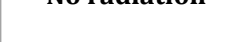 & Smokers & Non-smokers & Smokers & Non-smokers & \\
\hline $\begin{array}{c}\text { Number of } \\
\text { patients and } \\
\text { gender } \\
\text { distribution }\end{array}$ & $\begin{array}{c}148 \text { patients } \\
78 \text { female }(52.7 \%) \\
70 \text { male }(47.3 \%)\end{array}$ & $\begin{array}{c}19 \text { patients } \\
10 \text { female }(52.6 \%) \\
9 \text { male }(47.4 \%)\end{array}$ & $\begin{array}{c}29 \text { patients } \\
12 \text { female }(41.4 \%) \\
17 \text { male }(58.6 \%)\end{array}$ & $\begin{array}{c}31 \text { patients } \\
15 \text { female } \\
(48.4 \%) \\
16 \text { male }(51.6 \%)\end{array}$ & $\begin{array}{c}97 \text { patients } \\
55 \text { female }(56.7 \%) \\
42 \text { male }(43.3 \%)\end{array}$ & $\begin{array}{c}182 \text { patients } \\
97 \text { female } \\
(53.3 \%) \\
85 \text { male }(46.7 \%)\end{array}$ \\
\hline $\begin{array}{c}\text { Average age } \\
\text { (median) }\end{array}$ & $\begin{array}{c}56.5 \text { years } \\
\text { (median } 58.5 \text { ) }\end{array}$ & $\begin{array}{c}46.3 \text { years } \\
\text { (median } 51)\end{array}$ & $\begin{array}{c}52.4 \text { years } \\
\text { (median } 62.5 \text { ) }\end{array}$ & $\begin{array}{l}49.2 \text { years } \\
\text { (median } 59 \text { ) }\end{array}$ & $\begin{array}{l}57.5 \text { years } \\
\text { (median } 62 \text { ) }\end{array}$ & $\begin{array}{c}58.4 \text { years } \\
\text { (median } 61)\end{array}$ \\
\hline $\begin{array}{l}\text { Performed sinus } \\
\text { lifts }\end{array}$ & $\begin{array}{l}241 \text { sinuses } \\
153 \text { i.i.p. } \\
88 \text { d.i.p. }\end{array}$ & $\begin{array}{c}25 \text { sinuses } \\
9 \text { i.i.p. } \\
16 \text { d.i.p. }\end{array}$ & $\begin{array}{l}34 \text { sinuses } \\
24 \text { i.i.p. } \\
10 \text { d.i.p. }\end{array}$ & $\begin{array}{l}42 \text { sinuses } \\
29 \text { i.i.p. } \\
13 \text { d.i.p. }\end{array}$ & $\begin{array}{l}140 \text { sinuses } \\
91 \text { i.i.p. } \\
49 \text { d.i.p. }\end{array}$ & $\begin{array}{c}298 \text { sinuses } \\
190 \text { i.i.p. } \\
108 \text { d.i.p. }\end{array}$ \\
\hline $\begin{array}{l}\text { Number of } \\
\text { inserted } \\
\text { implants }\end{array}$ & 666 & 64 & 88 & 126 & 388 & 833 \\
\hline
\end{tabular}

Table 2: Patients that underwent radiation and/or chemotherapy with and without perforation of the Schneiderian membrane. Further, comparison of smokers and non-smokers within the groups (demographic and performance data).

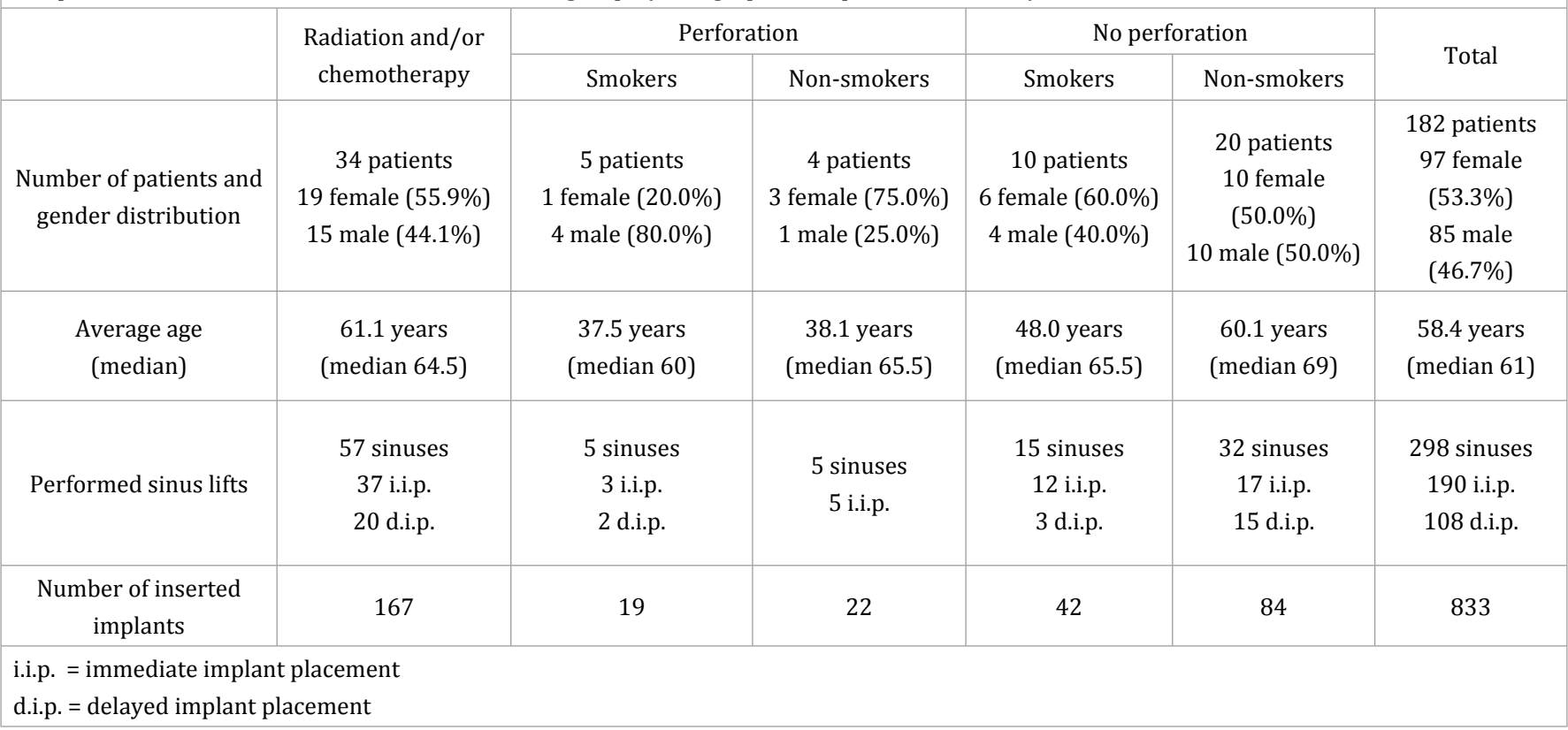


Series Study

Table 3: Evaluation of success rates, implant loss rates and perforation occurrence in non-irradiated patients with and without perforation of the Schneiderian membrane. Further, comparison of smokers and non-smokers within the groups (statistical analysis).

\begin{tabular}{|c|c|c|c|c|c|c|}
\hline & \multirow{2}{*}{ No radiation } & \multicolumn{2}{|c|}{ Perforation } & \multicolumn{2}{|c|}{ No perforation } & \multirow{2}{*}{ Total } \\
\hline & & Smokers & Non-smokers & Smokers & Non-smokers & \\
\hline $\begin{array}{c}\text { Success } \\
\text { rates }\end{array}$ & $\begin{array}{c}94.2 \%(\mathrm{p}<0.001) \\
227 \text { of } 241 \\
\text { augmented sinuses }\end{array}$ & $\begin{array}{c}88.0 \%(\mathrm{p}<0.001) \\
22 \text { of } 25 \\
\text { augmented sinuses }\end{array}$ & $\begin{array}{c}91.2 \%(\mathrm{p}<0.001) \\
31 \text { of } 34 \\
\text { augmented sinuses }\end{array}$ & $\begin{array}{c}95.2 \%(\mathrm{p}<0.001) \\
40 \text { of } 42 \\
\text { augmented sinuses }\end{array}$ & $\begin{array}{c}95.7 \%(\mathrm{p}<0.001) \\
134 \text { of } 140 \\
\text { augmented } \\
\text { sinuses }\end{array}$ & $\begin{array}{c}93.0 \% \\
(\mathrm{p}<0.001) \\
277 \text { of } 298 \\
\text { augmented } \\
\text { sinuses }\end{array}$ \\
\hline $\begin{array}{l}\text { Implant loss } \\
\quad \text { rates }\end{array}$ & $\begin{array}{c}4.8 \%(\mathrm{p}<0.001) \\
32 \text { losses at } 666 \\
\text { inserted implants }\end{array}$ & $\begin{array}{c}4.7 \%(\mathrm{p}<0.001) \\
3 \text { losses at } 64 \\
\text { inserted implants }\end{array}$ & $\begin{array}{c}6.8 \%(\mathrm{p}<0.001) \\
6 \text { losses at } 88 \\
\text { inserted implants }\end{array}$ & $\begin{array}{c}9.5 \%(\mathrm{p}<0.001) \\
12 \text { losses at } 126 \\
\text { inserted implants }\end{array}$ & $\begin{array}{c}2.8 \%(\mathrm{p}<0.001) \\
11 \text { losses at } 388 \\
\text { inserted } \\
\text { implants }\end{array}$ & $\begin{array}{c}7.1 \%(\mathrm{p}<0.001) \\
59 \text { losses at } 833 \\
\text { inserted } \\
\text { implants }\end{array}$ \\
\hline $\begin{array}{l}\text { Perforation } \\
\text { occurrence }\end{array}$ & $\begin{array}{c}24.5 \%(\mathrm{p}<0.001) \\
59 \text { perforations at } \\
241 \text { augmented } \\
\text { sinuses }\end{array}$ & & & & & $\begin{array}{c}23.2 \% \\
(\mathrm{p}<0.001) \\
69 \text { perforations } \\
\text { at } 298 \\
\text { augmented } \\
\text { sinuses }\end{array}$ \\
\hline
\end{tabular}

Table 4: Evaluation of success rates, implant loss rates and perforation occurrence in patients that underwent radiation and/or chemotherapy with and without perforation of the Schneiderian membrane. Further, comparison of smokers and non-smokers within the groups (statistical analysis).

\begin{tabular}{|c|c|c|c|c|c|c|}
\hline & \multirow{2}{*}{$\begin{array}{l}\text { Radiationand/or } \\
\text { chemotherapy }\end{array}$} & \multicolumn{2}{|c|}{ Perforation } & \multicolumn{2}{|c|}{ No perforation } & \multirow[t]{2}{*}{ Total } \\
\hline & & Smokers & Non-smokers & Smokers & Non-smokers & \\
\hline Success rates & $\begin{array}{c}87.7 \%(\mathrm{p}<0.001) \\
50 \text { of } 57 \\
\text { augmented sinuses }\end{array}$ & $\begin{array}{c}60.0 \%(\mathrm{p}=0.070) \\
3 \text { of } 5 \\
\text { augmented sinuses }\end{array}$ & $\begin{array}{c}100.0 \%(\mathrm{p}=0.015) \\
5 \text { of } 5 \\
\text { augmented sinuses }\end{array}$ & $\begin{array}{c}80.0 \% \\
(\mathrm{p}=0.001) \\
12 \text { of } 15 \\
\text { augmented } \\
\text { inuses }\end{array}$ & $\begin{array}{c}93.8 \% \\
(\mathrm{p}<0.001) \\
30 \text { of } 32 \\
\text { augmented } \\
\text { sinuses }\end{array}$ & $\begin{array}{c}93.0 \%(\mathrm{p}<0.001) \\
277 \text { of } 298 \\
\text { augmented sinuses }\end{array}$ \\
\hline Implant loss rates & $\begin{array}{c}16.2 \%(\mathrm{p}<0.001) \\
27 \text { losses at } 167 \\
\text { inserted implants }\end{array}$ & $\begin{array}{c}68.4 \%(\mathrm{p}=0.235) \\
13 \text { losses at } 19 \\
\text { inserted implants }\end{array}$ & $\begin{array}{c}22.7 \%(\mathrm{p}=0.016) \\
5 \text { losses at } 22 \\
\text { inserted implants }\end{array}$ & $\begin{array}{c}9.5 \%(\mathrm{p}<0.001) \\
4 \text { losses at } 42 \\
\text { inserted } \\
\text { implants }\end{array}$ & $\begin{array}{c}6.0 \% \\
(\mathrm{p}<0.001) \\
5 \text { losses at } 84 \\
\text { inserted } \\
\text { implants }\end{array}$ & $\begin{array}{c}7.1 \%(\mathrm{p}<0.001) \\
59 \text { losses at } 833 \\
\text { inserted implants }\end{array}$ \\
\hline $\begin{array}{l}\text { Perforation } \\
\text { occurrence }\end{array}$ & $\begin{array}{c}17.5 \%(\mathrm{p}<0.001) 10 \\
\text { perforations at } 57 \\
\text { augmented sinuses }\end{array}$ & & & & & $\begin{array}{c}23.2 \%(\mathrm{p}<0.001) \\
69 \text { perforations at } \\
298 \text { augmented } \\
\text { sinuses }\end{array}$ \\
\hline
\end{tabular}

On the whole, the patients treated with radiation and/or chemotherapy showed lower success rates for sinus augmentation and higher implants loss rates. The success rate decreased from $94.2 \%(\mathrm{p}<0.001)$ to $87.7 \%(\mathrm{p}<0.001)$ and the implant loss rate increased from $4.8 \%(\mathrm{p}<0.001)$ to $16.2 \%(\mathrm{p}<0.001)$.

As a comparable risk factor, smokers showed lower success rates and higher implant loss rates in all statistically significant group pairs of the final stage. Only the group of irradiated patients with perforated sinuses which was too small (less than 10 patients/augmented sinuses), failed to show significant results and thus was not considered for the ensuing discussion. The highest success and lowest implant loss rate were found in the group of patients not treated with radiation and/or chemotherapy that were nonsmokers and where no perforation of the Schneiderian membrane occurred. Here the success rate was at $95.7 \%(\mathrm{p}<0.001)$ and the implant loss at $2.8 \%(\mathrm{p}<0.001)$.

Except from the first pair of the third stage with perforated sinuses at irradiated patients, all groups showed statistically significant results and are investigated and discussed hereinafter. 


\section{Discussion}

Our study shows that perforations of the Schneiderian membrane (Figure 1C) during maxillary sinus augmentation have a statistically significant effect on overall implant survival. Although all perforations were covered with a resorbable collagen membrane, the failure and implant loss rates were significantly higher when the Schneiderian membrane was perforated. Within the 298 direct sinus lifts, a perforation of the Schneiderian membrane occurred in nearly one quarter $(23.2 \%$; $\mathrm{p}<0.001)$ of the augmentations [9]. Some predisposing factors for the occurrence of perforations could be found in the present literature $[14,15]$. Ardekian, et al. defined small residual ridge heights as an important factor, because it mostly leads to technical difficulties that are the reason for increased occurrences of perforations [12]. Other clinical aspects like the measurements of the access window seem to have no significant influence on the prognosis of augmentation [16]. Furthermore, the incidence of perforations seems to be dependent on the thickness of the Schneiderian membrane itself [17-20]. Rapani et al. for example described a membrane thickness of $2 \mathrm{~mm}$ and less as important determinant of perforation [20]. Other results like a study by Wen, et al. [19] also showed a dependence of perforations from membrane thickness, but described thicknesses of the Schneiderian membrane of more than $2 \mathrm{~mm}$ as pathological and therefore as an increasing factor for the occurrence of perforation [19]. Because cone-beam computed tomography scans were not available for all patients evaluated in this study, it was not possible to investigate this influential factor in our study. To reduce the occurrence of perforations, many authors nowadays use cone-beam computed tomography diagnostics to detect possible problems and pathologies with relevance for the following surgical procedure [21-23].

Overall it seems, that the use of resorbable collagen membranes alone, although they are widely used, do not have the desired improving influence on the prognosis of sinus membrane perforations. Some studies describe collagen membranes not to have important effects on wound healing [24-26]. When Schneiderian membrane perforations occur, an intensive aftercare with short-time evaluation is needed to ensure an adequate and early treatment [27]. A study of Proussaeffs et al. also investigated such cases and acquired similar results [28]. In their study levels of bone formation were higher for unperforated sinuses. Additionally, the implant survival rate was superior in unperforated sinus. They suggested that the use of collagen membranes in order to fix perforations might have an influence on the outcome, because bacteria may penetrate through the collagen membrane and induce infection of the graft material. Furthermore, they described that the operating surgeon is unable to control the coverage and position of his membrane, when graft material is filled into the cavity. This surely is and will remain an important clinical problem suggesting that the procedure needs to be improved in order to receive better results.

One possibility is the use of fibrin glue to securely fix the membrane to the perforation site. Of our 69 perforated sinus lifts, a total of 18 sinuses were repaired with a collagen membrane that was additionally fixed with fibrin glue. Within these 18 perforations only one case ended in a loss of grafting material. This would comply with a failure rate of $5.6 \%$. This is interesting in particular, because of the fact that fibrin glue was mostly used to support the coverage of greater perforations that would normally lead to a higher failure risk. The use of collagen membranes in combination with fibrin glue to fix the membrane safely onto the perforated area seems to have a positive impact and may neutralize the risk of perforations almost completely. Quite similar results were found by Cha, et al. [29], which also used resorbable membranes fixed with fibrin glue and did not find an adverse effect of perforations on the prognosis [29]. Becker et al. fixed collagen membranes with a suture, when perforations were larger than $5 \mathrm{~mm}$ [30]. The results showed no increased risk for perforated membranes.

The group of 18 patients in our study is relatively small and so was not investigated in detail. However, this could be a suggestion for further researches that may be able to yield an improving technique for the treatment of perforated sinuses.

Concerning our results, smoking is a risk factor for sinus augmentation, as well as for the implantation itself. Especially the perforation rates and the implant losses are significantly higher on smokers. For all groups with statistically significant results, the non-smokers showed the lowest rates for implant losses and highest success rates for sinus augmentation.

The influence of smoking on implantation and surgical operation procedures were extensively discussed and investigated in the past years [31-35]. The study of von Arx et al. showed an increase of perforation rate from $23.4 \%$ at non-smokers to $46.3 \%$ at smokers [36]. Strietzel, et al. reviewed 139 articles about the influences of smoking on dental implants, written between 1989 and 2005 [36,37]. They identified smoking as a significant risk factor and concluded that this is important for the preoperative patient information as well as for the postoperative recall. This fact seems to be extended by other anamnestic factors like a periodontitis anamnesis that are also increased by smoking as Uribarri, et al. described for bone losses after implantation [38]. Smokers that are treated with implants need to be informed about the possible complications, with smoking being one of few factors that can be eliminated. Nevertheless dentists or surgeons should schedule the patient in short periods for recalls, to recognize changes and complications in early stages. Apart from possibly increased failure and loss rates in smokers, wound healing takes longer when the wound is affected by smoking [32]. This would lead to longer and more frequent postoperative recall schemes for smokers compared to non-smokers. The 182 patients in our study were also surveilled within a strict and frequent recall system. Surely the influence of smoking depends on the amount of tobacco consumption and so is individual for all patients. Twito and Sade showed the influences of smoking in dependency on the amount of consumption [39]. They showed that the failure percentages rise with an increasing number of pack years. While non-smokers had a loss rate of about $3.5 \%$, smokers with one to 
five pack-years lost $4.3 \%$ of their implants and the patients with more than ten pack years had a loss rate of $8.0 \%$. Furthermore, they found that passive smoking had a negative influence on implant survival. Unfortunately, in our study, we could only divide patients into smokers and non-smokers. Therefore, we could only confirm the tendency of Twitto and Sade without being able to analyze our results finely.

In addition to implant survival, our results show that the failure rate of sinus augmentations is higher for smokers. Similar findings were found by Schwarz. et al. [26]. Few studies have investigated the influences of smoking on wound healing [4046]. Hematological effects as well as changes in blood pressure and the blood flow mainly cause this influence. The lower tissue perfusion and oxygenation of the blood leads to tissue hypoxia. Furthermore the aggregation potential of thrombocytes is decreased in smokers, because of a reduced production of prostacyclin. Nevertheless cigarette smoke and heat have direct effects on oral tissues and wounds. Knobloch, et al. found out that even a smoking cessation of 4 weeks can reduce risks significantly [47]. In addition, Bain, et al. investigated hemograms of smokers before and 2 weeks after smoking abstinence [48]. Hemoglobin, hematocrit and the numbers of red and white blood cells (except monocytes, eosinophils and basophils) fell significantly after 2 weeks. But not only does wound healing seem to be affected by smoking, the risk of peri-implantitis and thus the danger of later implant loss increases. Heitz-Mayfield, et al. described an increased peri-implantitis risk in a review published in 2009 [49]. Also Sayardoust, et al. described that smoking cessation is an important requirement for good implant survival and underlined distinct prognostic benefits of consequent non-smoking over the treatment period and beyond [50]. This shows that a cessation only for the time of implant insertion and wound healing is just a compromise, because well osseointegrated implants may also be affected by smoking.

In addition to the effects on wound healing, smoking-induced hypoxia and changes in the oral tissues and skin may also have an influence on the Schneiderian membrane. It should be mentioned that additionally to the results above, the average age of all smoker and non-smoker groups differs in the same way, so that the smoker groups are always younger. That means that the need for implantology emerges earlier for smokers, because of a higher risk of periodontitis and tooth loss that was also shown by many current investigations [51-55].

The failure and implant loss rate for maxillary sinus augmentations in patients who underwent radiation and/or chemotherapy, were significantly higher than in patients who had not received these therapies before surgery. Disturbances in wound healing after radiotherapy are frequently occurring problems in clinical practice. The immunosuppressive effects of these therapies and consequent decreased inflammatory potential are the main reasons for this effect. Haubner, et al. reviewed actual studies about the influences of radiotherapies on wound healing and explained all general effects of radiation on wound healing. Furthermore they illustrated different strategies for treatment of the irradiated wounds [56]. As radiation, chemotherapies also lead to an interference of the cell cycle and a reduced immunity. The main difference is that chemotherapies have a time limited systemic effect, while irradiation is always a more or less local treatment with lifelong effect on the tissue. Because of this, common influences of radiation and chemotherapy were investigated as one. As mentioned above, only radiation of the head and neck region was considered in our analysis.

Despite our results, implants are a reliable treatment for irradiated patients to get sufficient and acceptable results under certain prognostic limitations. Schiegnitz, et al. investigated implant survival on irradiated and non-irradiated patients and defined implant-supported concepts as valuable treatment also for irradiated patients [57].

\section{Conclusion}

Smoking as well as radiation and/or chemotherapy are substantial risk factors that decrease the prognosis of graft and implants. Patients who smoke should further be informed about the advantages of a smoking cessation for the time of postoperative healing. Despite the impact of smoking, radiation and chemotherapy, they are not contraindications for sinus augmentation or implantation.

Perforations of the Schneiderian membrane should be covered safely. Using collagen membranes to repair perforations is a successful method although it might be improved by the use of fibrin glue to fix the membrane in place. Although the overall failure and implant loss rates were still higher for perforated sinuses. Perforations covered with a collagen membrane fixed with fibrin glue showed higher success rates than those without fixation. Further research will follow in order to investigate this effect in detail. Based on our data, supplementary studies will also evaluate the influence of graft materials as well as preoperative alveolar ridge height on the outcome of sinus lift augmentation.

\section{Approval}

This retrospective study has been approved by the ethics committee of the medical faculty of the University of Duesseldorf (study number 4912).

\section{References}

1. Branemark PI. Vital microscopy of bone marrow in rabbit. Scand J Clin Lab Invest. 1959;11 Supp 38:1-82.

2. Branemark PI. Osseointegration and its experimental background. J Prosthet Dent. 1983;50(3):399-410.

3. Brånemark PI, Adell R, Breine U, Hansson BO, Lindström J, Ohlsson A. Intra-osseous anchorage of dental prostheses. I. Experimental studies. Scand J Plast Reconstr Surg, 1969;3(2):81-100.

4. Brånemark PI, Breine U, Hallén 0 , Hanson B, Lindström J. Repair of defects in mandible. Scand J Plast Reconstr Surg. 1970;4(2):100-108.

5. Brånemark PI, Hansson BO, Adell R, Breine U, Lindström J, Hallén O, Ohman A. Osseointegrated implants in the treatment of the edentulous jaw. Experience from a 10-year period. Scand J Plast Reconstr Surg Suppl. 1977;16:1-132. 


\section{Series Study}

6. Brånemark R, Brånemark PI, Rydevik B, Myers RR. Osseointegration in skeletal reconstruction and rehabilitation: a review. J Rehabil Res Dev. 2001;38(2):175-181.

7. Tatum H Jr. Maxillary and sinus implant reconstructions. Dent Clin North Am. 1986;30(2):207-229.

8. Purushotham S, Raveendran AM, Kripalani BK, D’Souza ML. Direct Sinus Lift and Immediate Implant Placement Using Piezosurgical Approach- A Case Report. J Clin Diagn Res. 2016;10(1):ZD20-ZD22. doi: 10.7860/JCDR/2016/16620.7150

9. Al-Dajani M. Incidence, Risk Factors, and Complications of Schneiderian Membrane Perforation in Sinus Lift Surgery: A Meta-Analysis. Implant Dent. 2016;25(3)::409-415. doi: 10.1097/ ID.0000000000000411

10. Moreno Vazquez JC, Gonzalez de Rivera AS, Gil HS, Mifsut RS Complication rate in 200 consecutive sinus lift procedures: guidelines for prevention and treatment. J Oral Maxillofac Surg. 2014;72(5):892-901. doi: 10.1016/j.joms.2013.11.023

11. Nolan PJ, Freeman K, Kraut RA. Correlation between Schneiderian membrane perforation and sinus lift graft outcome: a retrospective evaluation of 359 augmented sinus. J Oral Maxillofac Surg. 2014;72(1):47-52. doi: 10.1016/j.joms.2013.07.020

12.Ardekian L, Oved-Peleg E, Mactei EE, Peled M. The clinical significance of sinus membrane perforation during augmentation of the maxillary sinus. J Oral Maxillofac Surg. 2006;64(2):277-282.

13.Hernández-Alfaro F, Torradeflot MM, Marti C. Prevalence and management of Schneiderian membrane perforations during sinuslift procedures. Clin Oral Implants Res. 2008;19(1):91-98.

14. Yilmaz HG, Tözüm TF. Tozum, Are gingival phenotype, residual ridge height, and membrane thickness critical for the perforation of maxillary sinus? J Periodontol. 2012;83(4):420-425. doi: 10.1902/ jop.2011.110110

15.van den Bergh JP, ten Bruggenkate CM, Disch FJ, Tuinzing DB. Anatomical aspects of sinus floor elevations. Clin Oral Implants Res. 2000;11(3):256-265.

16. Baldini N, D’Elia C, Bianco A, Goracci C, de Sanctis M, Ferrari M. Lateral approach for sinus floor elevation: large versus small bone window - a split-mouth randomized clinical trial. Clin Oral Implants Res. 2017;28(8):974-981. doi: 10.1111/clr.12908

17. Janner SFM, Caversaccio MD, Dubach P, Sendi P, Buser D, Bornstein MM. Characteristics and dimensions of the Schneiderian membrane: a radiographic analysis using cone beam computed tomography in patients referred for dental implant surgery in the posterior maxilla. Clin Oral Implants Res. 2011;22(12):1446-1453.

18. Shanbhag S, Karnik P, Shirke P, Shanbhag V. Cone-beam computed tomographic analysis of sinus membrane thickness, ostium patency, and residual ridge heights in the posterior maxilla: implications for sinus floor elevation. Clin Oral Implants Res. 2014;25(6):755-760. doi: 10.1111/clr.12168

19. Wen SC, Lin YH, Yang YC, Wang HL. The influence of sinus membrane thickness upon membrane perforation during transcrestal sinus lift procedure. Clin Oral Implants Res. 2015;26(10):1158-1164. doi: 10.1111/clr.12429

20. Rapani M, Rapani C, Ricci L. Schneider membrane thickness classification evaluated by cone-beam computed tomography and its importance in the predictability of perforation. Retrospective analysis of 200 patients. Br J Oral Maxillofac Surg. 2016;54(10):11061110. doi: 10.1016/j.bjoms.2016.08.003

21. Tadinada A, Jalali E, Al-Salman W, Jambhekar S, Katechia B, Almas K. Prevalence of bony septa, antral pathology, and dimensions of the maxillary sinus from a sinus augmentation perspective: A retrospective cone-beam computed tomography study. Imaging Sci Dent. 2016;46(2):109-115. doi: 10.5624/isd.2016.46.2.109

22.Al-Dajani M. Recent Trends in Sinus Lift Surgery and Their Clinical Implications. Clin Implant Dent Relat Res. 2016;18(1):204-212. doi: 10.1111/cid.12275

23.Irinakis T, Dabuleanu V, Aldahlawi S. Complications During Maxillary Sinus Augmentation Associated with Interfering Septa: A New Classification of Septa. Open Dent J. 201711:140-150. doi: 10.2174/1874210601711010140

24.Scala A, Lang NP, Velez JU, Favero R, Bengazi F, Botticelli D. Effects of a collagen membrane positioned between augmentation material and the sinus mucosa in the elevation of the maxillary sinus floor. An experimental study in sheep. Clin Oral Implants Res. 2016;27(11):1454-1461. doi: 10.1111/clr.12762

25. Favero V, Lang NP, Canullo L, Urbizo Velez J, Bengazi F, Botticelli D. Sinus floor elevation outcomes following perforation of the Schneiderian membrane. An experimental study in sheep. Clin Oral Implants Res. 2016;27(2):233-240. doi: 10.1111/clr.12576

26.Schwarz L, Schiebel V, Hof M, Ulm C, Watzek G, Pommer B. Risk Factors of Membrane Perforation and Postoperative Complications in Sinus Floor Elevation Surgery: Review of 407 Augmentation Procedures. J Oral Maxillofac Surg. 2015;73(7):1275-1282. doi: 10.1016/j.joms.2015.01.039

27. Sakkas A, Konstantinidis I, Winter K, Schramm A, Wilde F. Effect of Schneiderian membrane perforation on sinus lift graft outcome using two different donor sites: a retrospective study of 105 maxillary sinus elevation procedures. GMS Interdiscip Plast Reconstr Surg DGPW. 2016;5:Doc11. doi: 10.3205/iprs000090

28.Proussaefs P, Lozada J, Kim J, Rohrer MD. Repair of the perforated sinus membrane with a resorbable collagen membrane: a human study. Int J Oral Maxillofac Implants. 2004;19(3):413-420.

29. Cha HS, Kim A, Nowzari H, Chang HS, Ahn KM. Simultaneous sinus lift and implant installation: prospective study of consecutive two hundred seventeen sinus lift and four hundred sixty-two implants. Clin Implant Dent Relat Res. 2014;16(3):337-347. doi: 10.1111/ cid.12012

30. Becker ST, Terheyden H, Steinriede A, Behrens E, Springer I, Wiltfang J. Prospective observation of 41 perforations of the Schneiderian membrane during sinus floor elevation. Clin Oral Implants Res. 2008;19(12):1285-1289. doi: 10.1111/j.1600-0501.2008.01612.x

31.Chrcanovic BR, Kisch J, Albrektsson T, Wennerberg A. Factors Influencing Early Dental Implant Failures. J Dent Res. 2016;95(9):995-1002. doi: 10.1177/0022034516646098

32. Sun C, Zhao J, Jianghao C, Hong T. Effect of heavy smoking on dental implants placed in male patients posterior mandibles: a prospective clinical study. J Oral Implantol. 2016;42(6):477-483. doi: 10.1563/ aaid-joi-D-16-00078 


\section{Series Study}

33. Barone A, Santini S, Sbordone L, Crespi R, Covani U. A clinical study of the outcomes and complications associated with maxillary sinus augmentation. Int J Oral Maxillofac Implants. 2006;21(1):81-85.

34.Levin L. Smoking may decrease the survival rate of dental implants placed in areas of maxillary sinus floor augmentation. J Evid Based Dent Pract. 2014;14(4):183-184.

35. Levin L, Schwartz-Arad D. The effect of cigarette smoking on dental implants and related surgery. Implant Dent. 2005;14(4):357-361.

36.von Arx T, Fodich I, Bornstein MM, Jensen SS. Perforation of the sinus membrane during sinus floor elevation: a retrospective study of frequency and possible risk factors. Int J Oral Maxillofac Implants. 2014;29(3):718-726. doi: 10.11607/jomi.3657

37. Strietzel FP, Reichart PA, Kale A, Kulkarni M, Wegner B, Küchler I. Smoking interferes with the prognosis of dental implant treatment: a systematic review and meta-analysis. J Clin Periodontol. 2007;34(6):523-544

38.Uribarri A, Bilbao E, Marichalar-Mendia X, Martínez-Conde R, Aguirre JM, Verdugo F. Bone Remodeling around Implants Placed in Augmented Sinuses in Patients with and without History of Periodontitis. Clin Implant Dent Relat Res. 2017;19(2):268-279. doi: 10.1111/cid. 12450

39. Twito D, Sade P. The effect of cigarette smoking habits on the outcome of dental implant treatment. PeerJ, 2014;2:e546. doi: 10.7717/peerj.546

40.Silverstein P. Smoking and wound healing. Am J Med. 1992;93(1A):22S-24S

41. Campanile G, Hautmann G, Lotti T. Cigarette smoking, wound healing, and face-lift. Clin Dermatol. 1998;16(5):575-578.

42. Towler J. Cigarette smoking and its effects on wound healing. J Wound Care. 2000;9(3):100-104.

43. Lane CA, Selleck C, Chen Y, Tang Y. The Impact of Smoking and Smoking Cessation on Wound Healing in Spinal Cord-Injured Patients With Pressure Injuries: A Retrospective Comparison Cohort Study. J Wound Ostomy Continence Nurs. 2016;43(5):483487. doi: 10.1097/WON.0000000000000260

44. Chiswell C, Akram Y. Impact of environmental tobacco smoke exposure on anaesthetic and surgical outcomes in children: a systematic review and meta-analysis. Arch Dis Child. 2017;102(2):123-130. doi: 10.1136/archdischild-2016-310687

45.Sorensen LT. Wound healing and infection in surgery: the pathophysiological impact of smoking, smoking cessation, and nicotine replacement therapy: a systematic review. Ann Surg 2012;255(6):1069-1079. doi: 10.1097/SLA.0b013e31824f632d
46.Patel RA, Wilson RF, Patel PA, Palmer RM. The effect of smoking on bone healing: A systematic review. Bone Joint Res. 2013;2(6):102111. doi: 10.1302/2046-3758.26.2000142

47. Knobloch K, Gohritz A, Reuss E, Vogt PM. [Nicotine in plastic surgery: a review]. Chirurg. 2008;79(10):956-962. doi: 10.1007/ s00104-008-1561-3

48. Bain BJ, Rothwell M, Feher MD, Robinson R, Brown J, Sever PS. Acute changes in haematological parameters on cessation of smoking. J R Soc Med. 1992;85(2):80-82.

49. Heitz-Mayfield LJ, Huynh-Ba G. History of treated periodontitis and smoking as risks for implant therapy. Int J Oral Maxillofac Implants. 2009;24 Suppl:39-68.

50.Sayardoust S, Gröndahl K, Johansson E, Thomsen P, Slotte C. Implant survival and marginal bone loss at turned and oxidized implants in periodontitis-susceptible smokers and never-smokers: a retrospective, clinical, radiographic case-control study. J Periodontol. 2013;84(12):1775-1782.

51. Bahrami G, Vaeth M, Kirkevang LL, Wenzel A, Isidor F. The impact of smoking on marginal bone loss in a 10-year prospective longitudinal study. Community Dent Oral Epidemiol. 2016. doi: 10.1111/cdoe.12260

52. Dietrich T, Walter C, Oluwagbemigun K, Bergmann M, Pischon T, Pischon N, et al. Smoking, Smoking Cessation, and Risk of Tooth Loss: The EPIC-Potsdam Study. J Dent Res. 2015;94(10):1369-1375.

53. Natto ZS, Aladmawy M, Alasqah M, Papas A. Factors contributing to tooth loss among the elderly: A cross sectional study. Singapore Dent J. 2014;35:17-22. doi: 10.1016/j.sdj.2014.11.002

54.Saaby M, Karring E, Schou S, Isidor F. Factors influencing severity of peri-implantitis. Clin Oral Implants Res. 2016;27(1):7-12. doi: 10.1111/clr.12505

55.Simila T, Auvinen J, Timonen M, Virtanen JI. Long-term effects of smoking on tooth loss after cessation among middle-aged Finnish adults: the Northern Finland Birth Cohort 1966 Study. BMC Public Health. 2016;16(1):867. doi: 10.1186/s12889-016-3556-1

56.Haubner F, Ohmann E, Pohl F, Strutz J, Gassner HG. Wound healing after radiation therapy: review of the literature. Radiat Oncol. 2012;7:162. doi: 10.1186/1748-717X-7-162

57. Schiegnitz E, Al-Nawas B, Kämmerer PW, Grötz KA. Oral rehabilitation with dental implants in irradiated patients: a metaanalysis on implant survival. Clin Oral Investig. 2014;18(3):687698. doi: 10.1007/s00784-013-1134-9 